\title{
BRIDGE PLATING OF COMMINUTED SHAFT OF FEMUR FRACTURES
}

\author{
Mohammad Abul kalam, Pradeep Kumar, Mohammad Afzal Hussain \\ and Iqbal Ahmad
}

\begin{abstract}
A prospective study of forty comminuted femoral shaft fractures, open and close, treated with a relatively minimally invasive technique termed as bridge plate osteosynthesis or biological fixation. Less invasive procedure, Short operative time and less blood loss was seen during surgical procedure. This prospective study was conducted at Nobel Medical College, Biratnagar from 2010 to 2011. This study was done because most of the femoral shaft fractures treated under C-arm mobile image intensifier but bridge plating system does not require such advanced costly equipment. Almost all cases were free from long term complications. All fractures healed within 6 months. Bone grafting was done for 2 cases as a secondary procedure. The complication of infections was seen in two of open fractures. This procedure can easily be carried out in general operating table by appropriable surgeons.
\end{abstract}

Key words: Comminuted femoral shaft fractures, Broad DCP, Interlocking plate.

\section{Introduction}

Shaft of femoral fractures are very common. Fixation of fractures is necessary to achieve function of limb as soon as early. Common problems of shortening of the limb, malalignment and contracture of knee can be prevented by reliable anatomic fixation and early mobilization. The treatment method selected should not cause increased systemic or local complications in an attempt to achieve these goals. Comminution and instability of this fracture makes the management more complex and open fractures of the femoral shaft also represent the extreme end of the spectrum of femoral shaft injuries. Comminuted fractures has high propensity to heal with shortening of malrotation if their degree of instability is not recognized appropriately.

Bridge plating of femoral shaft fractures are regarded as the best technique for comminuted fracture because without opening the fracture area stabilizes the fractures with a plate. It provides tissue conservation and does not disturb the vascularity of fracture sites.

\section{Materials and Methods}

In this prospective study, 40 comminuted femoral fractures were managed by bridge plating during the years April 2010 to June 2011.

Type III and IV comminuted ${ }^{1}$ fractures and type I open comminuted ${ }^{2}$ fractures were included while type I and II comminuted femoral shafts fractures and open Type II and Type III femoral shaft fractures and segmental femoral shaft fractures were excluded.

\section{Surgical technique}

All patients were operated by placing them in supine position. Two separate incisions were made to expose proximal and distal fragments, in straight line joining the greater trochanter and lateral femoral condyl. 
Fracture area remained untouched. The plate was threaded under the vastus lateralis from one incision to emerge through the other bridging the fracture sites then it was fixed with screw. After closing wounds and antiseptic dressing, postoperative management was started.

Operated limb for all patients were kept with knee flexed from 45 to 90 degree. Intravenous antibiotics were started to all patients. According to patient's improvement on first post operative day, gentle range of motion exercises of the knee and hip were started. Quadriceps exercises were soon encouraged. Touchdown ambulation was started on third or forth postoperative day (depending upon the pain) with the help of crutches. Partial weight bearing was allowed when early callus formation was seen and full weight bearing when bridging callus was seen weaning the use of crutches. All cases were followed up for at least six months to be included in the study.

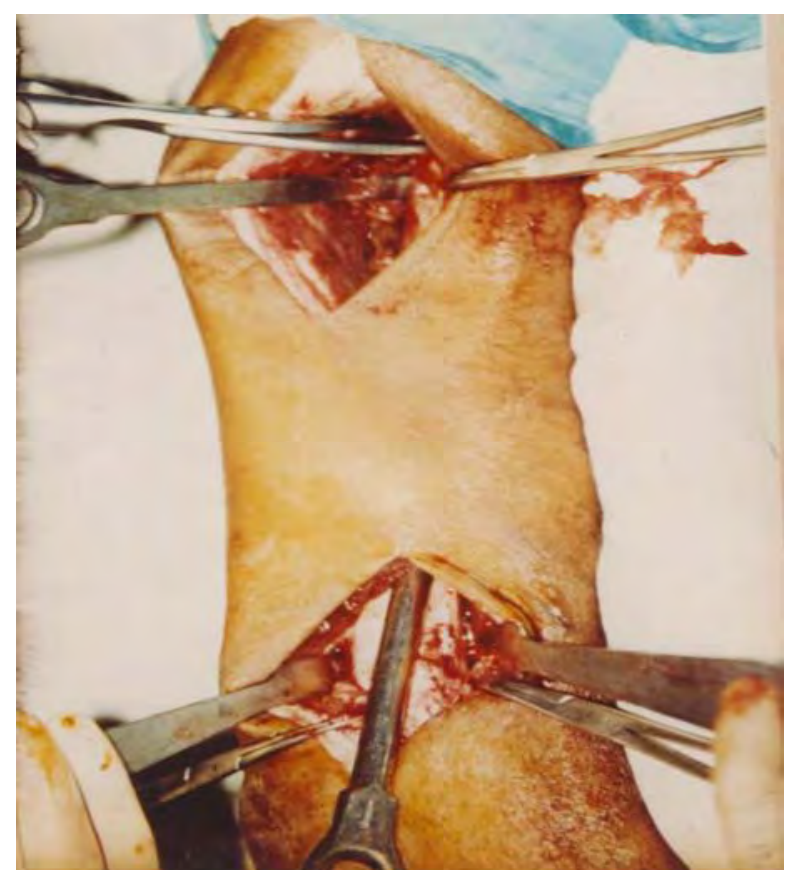

Photo 1: Bone segments exposed, tunnel being made beneath the vastus lateralis

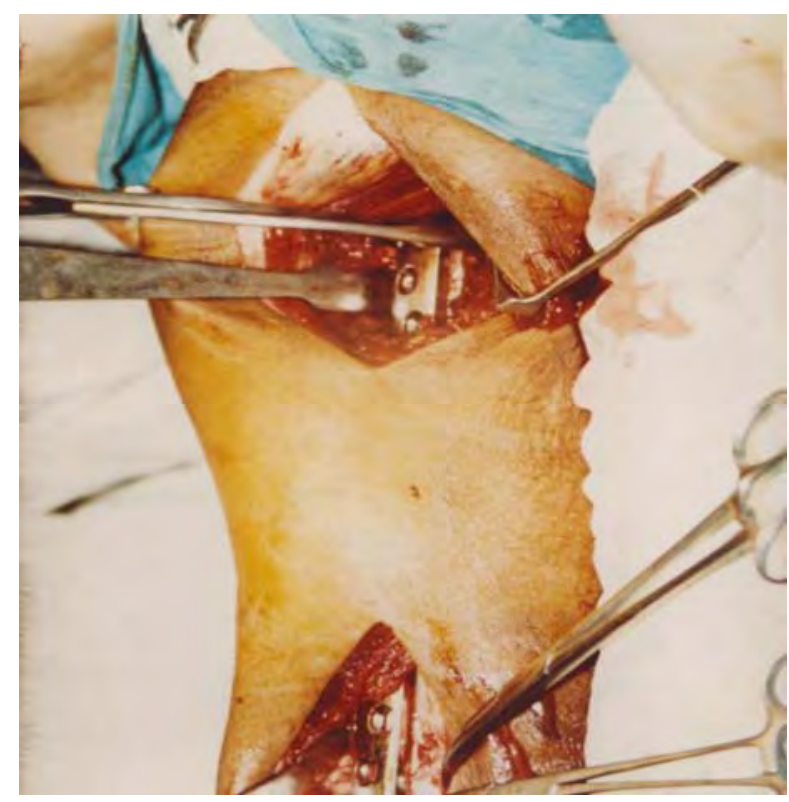

Photo 2: Plate having been inserted from proximal to distal segment

\section{Results}

We had 40 cases of bridge plating. There were 34 male and 6 female patients with male to female ratio 5.6:1.The major patient population is of age group between20-29 yrs. (table 1)

Table 1 : Age and sex distribution

\begin{tabular}{lll}
\hline Age group & Male & Female \\
\hline $20-29$ & 24 & 0 \\
$30-39$ & 4 & 4 \\
$40-49$ & 2 & 2 \\
$50-59$ & 4 & 0 \\
\hline
\end{tabular}

Table 2: open and close fractures

\begin{tabular}{lll}
\hline Open and close & number & percentage \\
\hline Close & 24 & $60 \%$ \\
open & 16 & $40 \%$ \\
\hline
\end{tabular}

There were equal numbers of patients each in grade III and IV comminution. In 12 (30\%) patients there were other concomitant injuries (table 3) and associated medical illness of 
hypertension or diabetes mellitus was found in $10(25 \%)$ patients. These were fairly controlled before operative procedure was carried out.

\section{Table 3. Concomittant injuries}

\begin{tabular}{lll}
\hline Injury & number & percentage \\
\hline Head injury & 2 & $16.6 \%$ \\
Chest injury & 2 & $16.6 \%$ \\
Upper limb & 2 & $16.6 \%$ \\
Ipsilateral lower limb & 4 & $33.3 \%$ \\
contralateral lower & 2 & $16.6 \%$ \\
limb & & \\
\hline total & 12 & \\
\hline
\end{tabular}

All the fractures were healed by 24 weeks after surgical procedure (Table 4)

Table 4. Fractures healing time

\begin{tabular}{|c|c|c|}
\hline $\begin{array}{l}\text { Time in } \\
\text { weeks }\end{array}$ & $\begin{array}{l}\text { No of fractures } \\
\text { healed }\end{array}$ & percentage \\
\hline 12 & 0 & 0 \\
\hline 14 & 2 & 5 \\
\hline 16 & 2 & 5 \\
\hline 18 & 8 & 20 \\
\hline 20 & 22 & 55 \\
\hline 22 & 2 & 5 \\
\hline 24 & 4 & 10 \\
\hline total & 40 & \\
\hline
\end{tabular}

There were four (10\%) wound infections. All of these were open fractures. The same patients got knee stiffness and range of motion in 90 to 120 degree. There was also shortening of 1 to $3 \mathrm{~cm}$ in 3 cases (7.5\%) of grade IV comminuted fractures.

\section{Discussion}

Almost all fractures shaft of femur need procedure with help of image intensifier, special instrumentation and orthopaedic traction table. So such expensive equipment which can't be afford by many hospitals in developing countries. It therefore seems necessary to make an attempt to explore an alternative cheap method for managing these types of fractures. At the same time, bridge plating of comminuted femoral shaft fractures is safe, easy, versatile and superior method of internal fixation of these difficult fractures. This does not require such elaborate instrumentation $^{3}$.

The advantages obtained by bridge plating are that the vascularization of the fragments is optimally preserved. The new concept aims at minimal surgical damage to the blood supply, maintenance of optimal bone structure near the implant, improved healing in the critical zone in contact with the plate, minimal damage to the bone lining at plate removal with reduced risk of refracture and optimal tissue tolerance of the implant by selection of pure titanium as implant material ${ }^{4}$. The conflict between the need for absolute anatomical reduction and the desire for soft tissue preservation in analogues to the saying 'wash me but don't get me wet,' the slow progress towards improved soft tissue handling is evidenced by the way plating techniques are taught.

Heitemeyer et $\mathrm{al}^{5}$ developed the bridge plate fixed proximally and distally along the bone. Bridging plate technique decreases vascular disruption at the fracture site altering the load of the plate to provide pure tension forces on the plate. ${ }^{6}$

Kleining and $\operatorname{Max}^{7}$ developed the techniques of bridge plating osteosynthesis for severely comminuted femoral fractures and they stabilize the fractures with a plate, without opening the fractures area. The bridging plate osteosynthesis guarantees sufficient stability for early physiotherapy

In bridge plate technique above \& below the fracture with the use of plates inserted deep to the muscles. ${ }^{8}$ Bridge plating is a technique of biological fixation as it does neither interfere with the fracture hematoma nor it causes 
periosteal or soft tissue stripping from small fracture fragments. It aims at indirect reduction without further devascularization of bone pieces achieving perfect alignment rather than anatomical reduction of extra articular fractures, optimal rather than maximal internal fixation. This requires reduction and fixation techniques which do not cause additional damage to the vitality of the bone. The operative technique is comparatively easy and can perform within about one hour. The concept of biological osteosynthesis refers basically to the conservation of the vascularity of the bone during surgical intervention to ensure the continued vitality of the individual fragments and to achieve improved fracture healing. The main methods of treatment are indirect reduction and bridge plating. ${ }^{9}$

Bridge plating with its advantages in terms of vascularity and bone healing is a well established procedure today in the treatment of comminuted femoral fractures 10

In our study fractures healing time was 19.6 weeks. This time varies in different studies from 16 to 23 weeks.

Table 5. Studies showing fracture healing

\begin{tabular}{lc}
\hline Studies & Time of healing \\
\hline Heitemeyer et al (1987) & 23 weeks \\
Wenda et al (1997) & 16 weeks \\
Maini (1997) & 17 weeks \\
Chrisovitsinos et al (1997) & 20 weeks \\
Present study & 19.6 weeks \\
\hline
\end{tabular}

In our study there were some complications like wound infection, knee stiffness and shortening but there was no case of nonunion or implant failure. There were 4 cases of wound infection both of the infections were in open fractures. At the end of 6 months, 4 patients could not flex their knees beyond 100 degrees. There were 6 cases with shortening of $1-3 \mathrm{~cm}$.

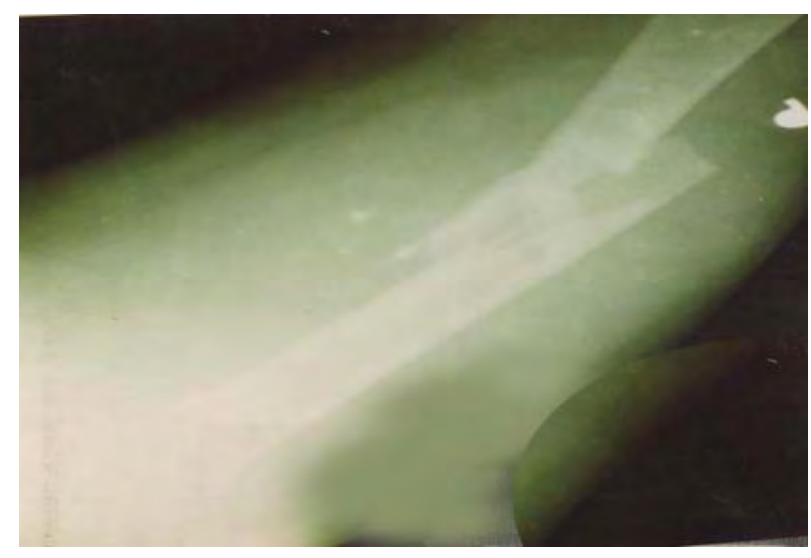

Photo 3: X-ray showing pre-operative anteroposterior view

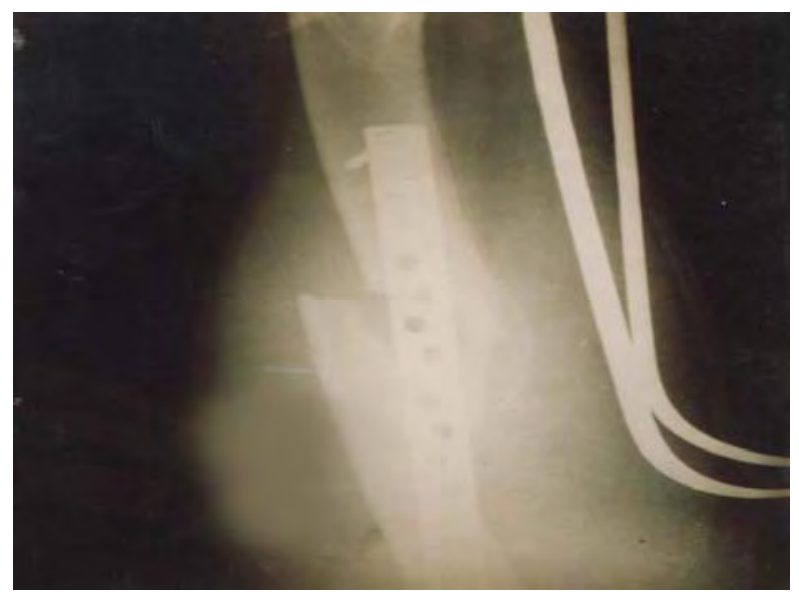

Photo-4 :X-ray showing immediate postoperative lateral view

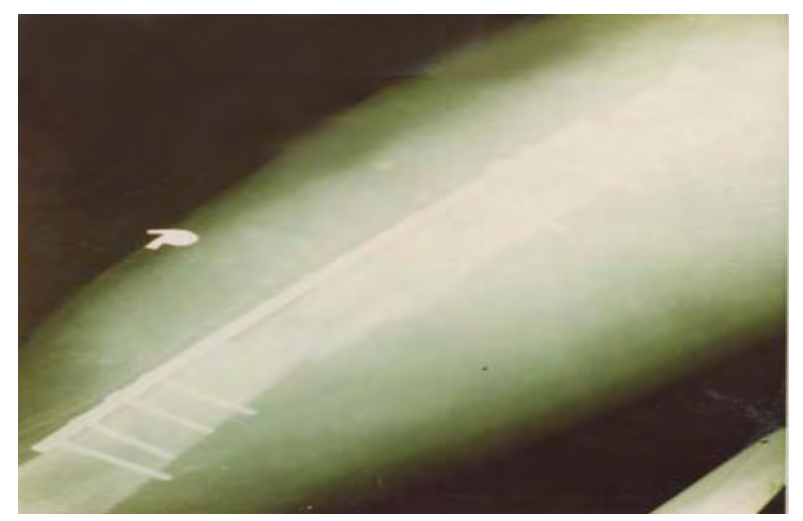

Photo5 : X-ray showing immediate postoperative antero-posterior view 


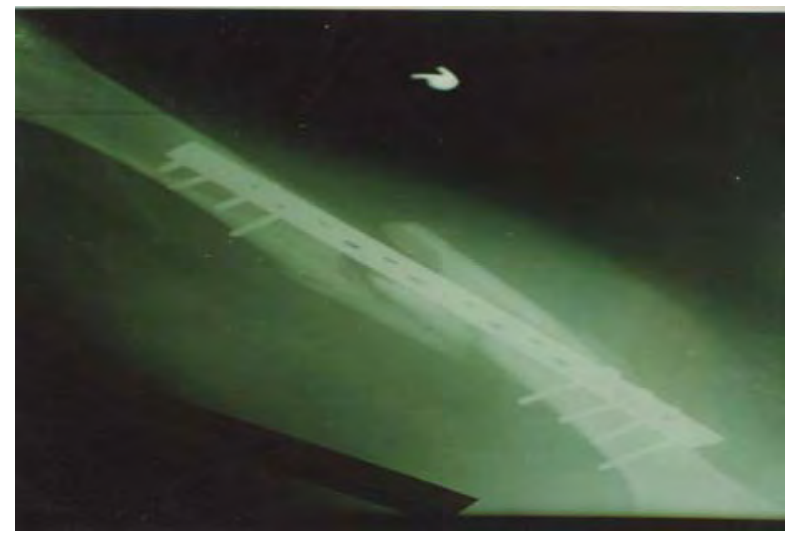

Photo 6 : X-ray showing 12 weeks postoperative lateral view

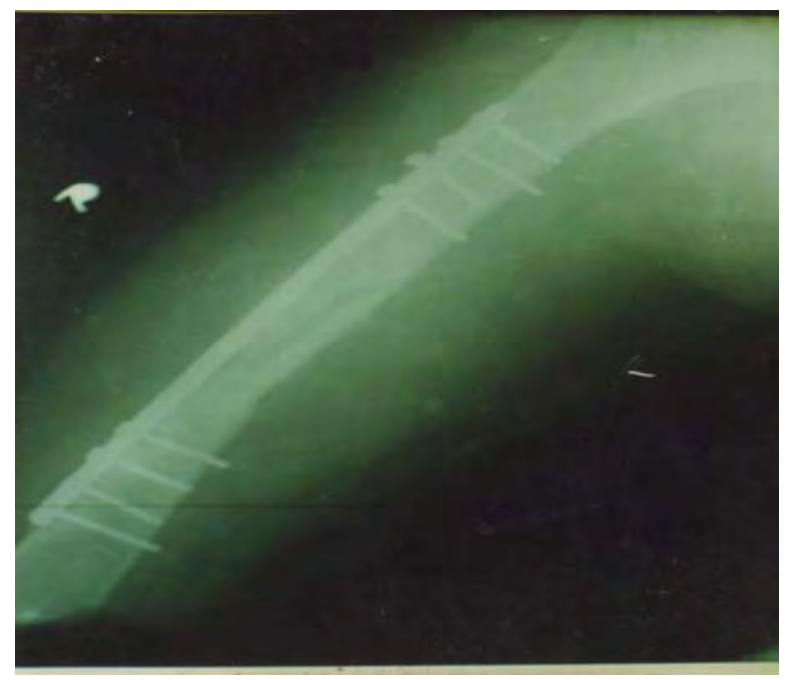

Photo 7 : X-ray showing12 weeks post-

Photo 9 : Postoperative X-ray showing(18 weeks ) anticipated delayed union Antero posterior view

operative antero posterior view

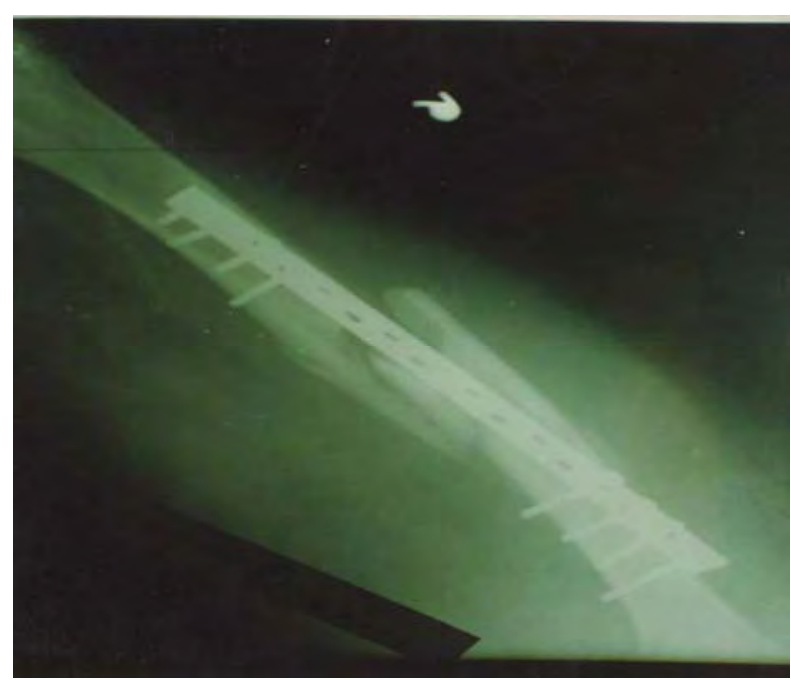

Photo 8 : Postoperative X-ray showing(18 weeks ) anticipated delayed union lateral view

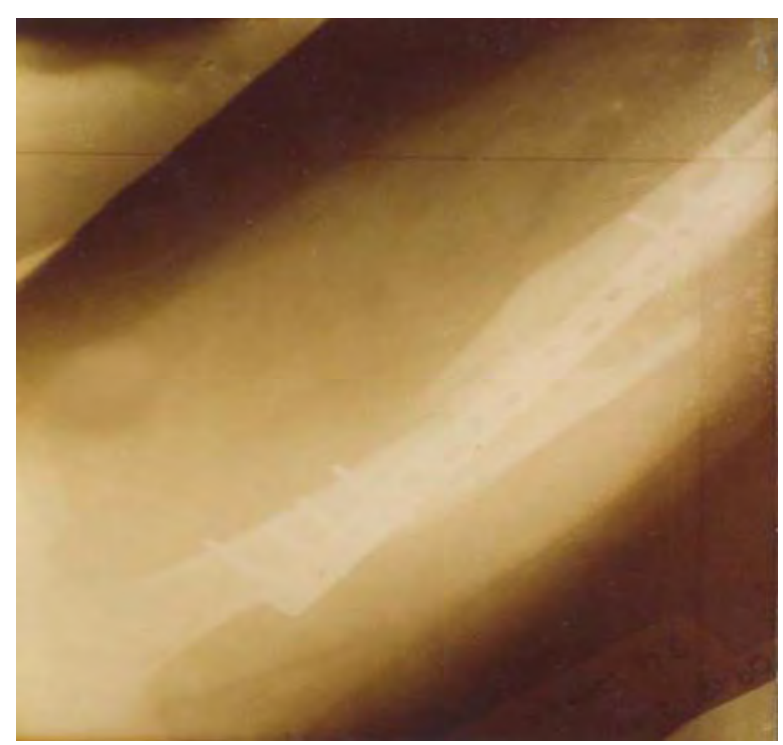

Photo 10: Postoperative X-ray showing (24 weeks) union after bone grafting lateral view 


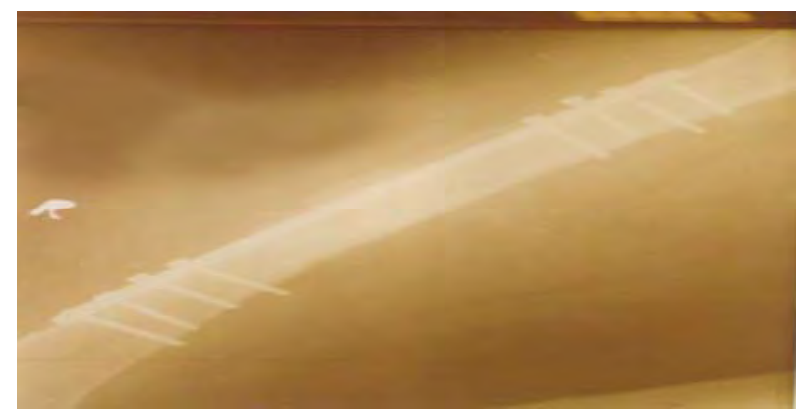

Photo 11: Postoperative X-ray showing (24 weeks) union after bone grafting antero posterior view.

\section{Conclusion}

Bridge plating of comminuted shaft of femur fracture is a very good procedure in our part of the world, where we have to work with the existing insufficient resources. This should be done even in teaching hospitals where all the facilities may be available.

\section{References}

1. Winquist RA, Hansen ST Jr, Comminuted fracture of the femoral shaft treated by intramedullary nailing. Orthop Clin north Am 1980; 11(3):633-48.

2. Gustilo RB, Mendoza RM, Williams DN. Problems in the management of type III (severe) open fractures. A New classification of type III open fractures. J trauma 1984:24:742-46.

3. Maini PS. Biological fixation of comminuted Femoral Shaft fractures follow up study of nine years.J Pak Orthop Assoc 1997:9 (suppl):39-42

4. Perren SM, Allgower M, Brunner $\mathrm{H}$, et al (eds). The concept of biological plating using the limited contact dynamic compression plate (LCDCP): scientific background, design and application. Injury 1991; 22(suppl 1):1-40.

5. Heitemeyer U, Kemper F, Hierholzer G, Haines J. Severly comminuted femoral shaft fractures: Treatment of bridge plate osteosynthesis. Arch orthop trauma surg 1987; 106: 327-30.

6. Miclan T, Martin RE, The evolution of modern plate osteosynthesis. Injury 1997; 28 (suppl 1): SA 3-6.

7. Kleining R, Hax PM. Severely comminuted femoral shaft fractures: Treatment by bridging plate osteosynthesis.Arch orthop trauma surg 1981;153:213

8. Krettek C. Concepts of minimally invasive plate osteosynthesis. Injury 1997; 28 (suppl 1): SA 1-2.

9. Baumgaertel F, Buhl M, Rahn BA. Fracture healing in biological plate osteosynthesis. Injury 1998;29 (suppl3): SC 3-6

10. Wenda K, Runkel M, Degreif $\mathbf{J}$, Rudig $\mathbf{L}$. Minimally invasive plate fixation in femoral shaft fractures. Injury 1997; 28 (suppl1): SA 13-19

11. Chrisovitsinos JP, Xenakis T, Papakostides KG, Skaltsoyannis N, Grestas A, Soucacos PN. Bridge plating osteosynthesis of 20 comminuted fractures of the femur. Acta orthop scand 1997; 68 (suppl 275) :72-76

Correspondence address; Dr. Abul Kalam Mohammad, Orthopaedic Surgeon, E-mail: shahinshekh@yahoo.com, cell phone : 9852026774, Biratnagar 